\title{
Stucco repair method for enclosing brick walls
}

\author{
Alexandr Zholobov ${ }^{1}$, Nadezhda Ivannikova ${ }^{2, *}$, Olga Razinkova ${ }^{2}$, and Peter Dukhanin ${ }^{1}$ \\ ${ }^{1}$ Don State Technical University, 344000, 1 Gagarin Square, Rostov-on-Don, Russia \\ ${ }^{2}$ Astrakhan State University Architectural and Civil Engineering, 414056, 18 Tatishcheva, St., \\ Astrakhan, Russia
}

\begin{abstract}
During the operation of buildings, plaster coatings of the external and internal enclosing surfaces of brick walls are subjected to various destructive influences. Existing methods of repairing plaster coatings do not fully ensure strong adhesion of the material of the repair layer of plaster to the surface of the repaired brick wall structure. In addition, these methods can only get rid of damage but do not improve the operational properties of the plaster layer of the repaired structure. Thus, the urgent problem is the development of an effective method of repairing plaster coatings on the surfaces of brick walls, due to which it will become possible to ensure the monolithic of the repaired plastering structure. In order to address the shortcomings of the existing plaster coating repair techniques on the surfaces of the brick walls and finding ways to improve it, by the authors investigated the possibility and the expediency of performing the repair of additional process steps. A feature of this repair method is the use of preheated plaster mortar, flexible plaster molding, as well as compaction of the stucco mortar in the contact area with the repaired brick wall structure with a deep plate compactor. The test results of samples of plaster coatings manufactured by the proposed method showed the high efficiency and feasibility of using this method for repairs on the external and internal surfaces of walling of brick walls and are mentioned in the patent for the invention of the Russian Federation. The performance characteristics of the plaster are significantly increased as a result of the application of this method, and, consequently, the service life of the plaster coating is increased several times.
\end{abstract}

\section{Introduction}

Long-term experience in the operation of buildings with plastered external walls shows that the service life of the plaster is several times less than the service life of the brick walls, so there is a need to periodically repair or change the plaster coating due to considerable wear and tear.

Questions on the study of plaster coatings are indicated in the works of many Russian and foreign scientists such as Ataev SS, Badyan GM, Verstov VV, Khaykovich DM, Shreiber M., Ross H., Stahl F. and others, including foreign sources [1-6]. Along with the

\footnotetext{
*Corresponding author: n.a.ivannikova.88@gmail.com
} 
current scientific knowledge, there is also a large number of standards and normative technical documentation.

One of the most reliable technologies repair plaster layer to not long ago, it was thought spraying, providing a sufficiently strong adhesion of the repair layer material with the repaired structure. However, this method is expensive, material and energy-intensive. Besides, it does not provide a smooth surface and a uniform density repair layer on its thickness, since the closer to the surface plated layer usually has a lower strength and more porous structure than in the zone of its contact with the plaster layer of the repaired structure, which is extremely undesirable for outdoor structures.

The main signs of physical deterioration of the facade plaster are partial or complete detachment from the brickwork, cracks, peeling, and erosion of the surface layer, as well as destruction of the plaster material. A general view of the damage to the plaster coating on the surface of the walling of brick walls shown in Fig. 1.

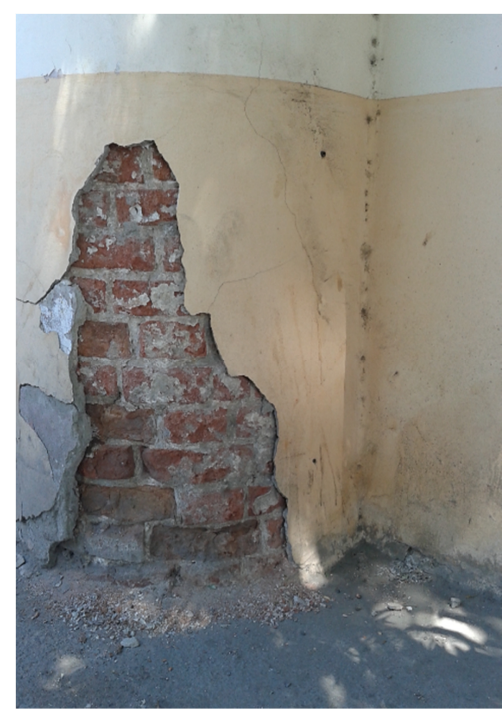

a)

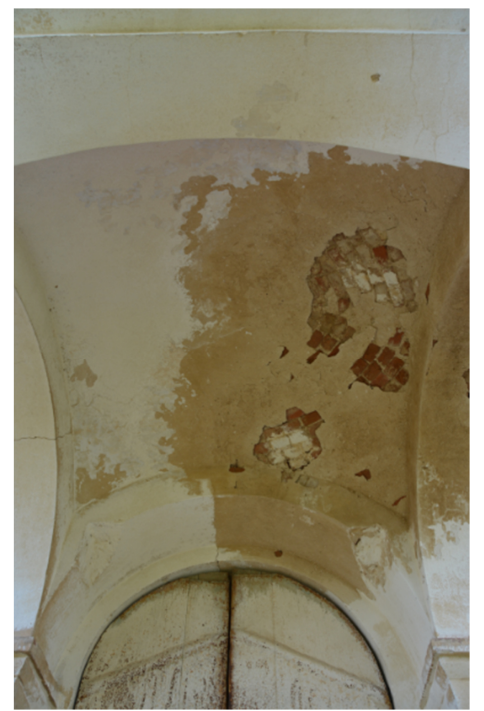

b)

Fig. 1. Image of damaged plastered brickwork surfaces of the Cathedral of the Mother of God, Astrakhan Region, Russia: a) The damaged plastered external of walls; b) The damaged external structure adjacent to the dome.

Smooth surface layer structure and a relatively uniform material applied to the repaired portion of the structure, conventional plastering can access it. However, this method was not widely used because of the poor adhesion of the new plaster to the old, which, as a rule, does not exceed the recommended. In addition, these methods only allow to get rid of damage but do not improve the operational properties of the repaired structure.

To resolve the first of these drawbacks is sometimes applied to the adhesive layer on the surface of the structure to be repaired, for example, from cement or epoxy activated composition. Some improvement in the performance properties of the repair layer is achieved by using a blend with a low water-cement ratio. This allows you to reduce the shrinkage of the material of the protective layer and increase its water resistance.

In recent years, when choosing a rational option for plastering repair technology on the exterior and interior surfaces of brick walls in the repair and construction industry, preference is increasingly being given to a method based on the use of special repair compounds with enhanced adhesion and water resistance. Its advantages include simplicity of molding and the possibility of obtaining a smooth surface of the protective layer. The 
disadvantages of the method are the high cost of repair, and most importantly, poor compatibility of the material of the repair layer with the material of the structure being repaired due to deformation properties, which can lead to pre-temporary peeling of the protective layer during operation of the repaired structure outdoors.

Given the above, we can conclude that the problem of plaster coating repair technology on the surfaces of brick walls is the lack of effective methods and means to ensure the integrity of the repaired structure and aggressive influence against the plaster coatings.

\section{Materials and Methods}

It was established that the destruction of the plaster coating located on the walling of brick walls occurs as a result of aggressive environmental influences, presented in the table.

Table 1. Classification of aggressive influence against the plaster coatings.

\begin{tabular}{|c|c|c|c|}
\hline № & $\begin{array}{l}\text { The influence } \\
\text { kind }\end{array}$ & The aggressive determinant & The destruction action \\
\hline \multirow[t]{2}{*}{1} & \multirow[t]{2}{*}{ Mechanical } & Strong wind & The plaster coating's erosion \\
\hline & & «Human factor» & $\begin{array}{c}\text { Sloppy operation, scratches, } \\
\text { bumps, vibration }\end{array}$ \\
\hline \multirow[t]{2}{*}{2} & \multirow[t]{2}{*}{ Physical } & $\begin{array}{l}\text { Water (rain and melt water, } \\
\text { condensate, snowfall, frost) }\end{array}$ & $\begin{array}{l}\text { Hydrodynamic pressure } \\
\text { against the plastered surface } \\
\text { caused by falling water } \\
\text { energy. } \\
\text { Water intrusion (including } \\
\text { through the damaged roof) } \\
\text { into the material's pores of the } \\
\text { plastered coating with its } \\
\text { further swelling, peeling and } \\
\text { exfoliation, water soluble } \\
\text { component's washout of the } \\
\text { binding }\end{array}$ \\
\hline & & $\begin{array}{l}\text { The surrounding temperature } \\
\text { fluctuation }\end{array}$ & $\begin{array}{l}\text { The temperature deformations } \\
\text { cause the crack opening and } \\
\text { the plaster coating's } \\
\text { exfoliation. Ice formation due } \\
\text { to the water freezing into the } \\
\text { plaster coating's pores and } \\
\text { cavities. The plaster surface's } \\
\text { icing due to the melt water's } \\
\text { icing. }\end{array}$ \\
\hline 3 & Chemical & $\begin{array}{l}\text { Crystallization of harmful } \\
\text { salts into the plaster coating's } \\
\text { pores and surfaces. }\end{array}$ & $\begin{array}{l}\text { Example, carbonation of the } \\
\text { binder that causes the plaster } \\
\text { coating's damage. }\end{array}$ \\
\hline 4 & Biological & $\begin{array}{c}\text { Microorganisms (fungi, } \\
\text { bacteria, lichens, mosses) }\end{array}$ & $\begin{array}{l}\text { Plaster mortar's biocorrosion. } \\
\text { Destruction of the plaster } \\
\text { coating's material. }\end{array}$ \\
\hline
\end{tabular}

In order to eliminate drawbacks of the technology of repairing plaster coating on the surfaces of brick walls and finding ways to improve it, and In order to eliminate aggressive influence against, the authors of the article investigated the possibility and proved the feasibility of performing additional technological operations during the repair, including: 
1. Vibration treatment of freshly laid fine-grained plaster mix in the contact zone with the old solution using a slowly moving immersion vibrator, the working body of which is a plate, vibrating in the longitudinal direction of movement;

2. Pre-heating the plaster immediately before applying it to the structure being repaired;

3. Keeping the plaster layer in the process of hardening under the air-tight fi.

It was established experimentally that the impact of the vibrating plate on the plaster mix in the contact zone with the surface of the repaired structure contributes to the vibration activation of the cement, since the vibration treatment destroys the coagulation structures of the cement grains and the dispersion processes occur more actively as a result of which the hydration reactions of the cement with the forming a more dense cement stone structure.

Vibrations of the plaster mixture in the contact zone with the surface of the structure to be repaired, in addition, leads to the fluidized that provides a more effective seal it in said zone.

Moving in a layer of freshly applied plaster, the vibrating plate carries with it (due to the dilution formed after it) air bubbles present in the solution, which also contributes to the formation of a more dense structure of the plaster layer in the contact zone.

The optimal values of the thickness and speed of movement of the vibro plate at the oscillation frequency of $50 \mathrm{~Hz}$ are determined. It has been established that the use of a deep seal with a plate vibrator can increase the adhesion of the plaster layer several times.

The vibrator construction is the manual electromagnetic vibrator and specially constructed vibration plate connected to each other. The vibration plate's thickness is 2 $\mathrm{mm}$, its length is $20 \mathrm{~mm}$, its width is $5 \mathrm{~mm}$, its speed shift is $10 \mathrm{~mm} / \mathrm{s}$, the distance between the vibration plate and the surface of the «basis» construction is $5 \mathrm{~mm}$. The vibration plate's oscillations are directed along to the «basis» construction, while their frequency is $50 \mathrm{~Hz}$ that is average frequency of the most electric vibrators for the general purpose.

In the course of the experiments, a positive effect on increasing the adhesion of the plaster layer prior to heating the solution to a temperature of $40-80^{\circ} \mathrm{C}$ was proved, as a result of which the surface tension of the mixing water decreases many times and, as a result, the mobility of the heated plaster increases, which contributes to its better compaction. The positive role of preheating the plastering solution is also to enhance the effect of contraction sealing of the concrete repair layer and favorable mass transfer processes in the area of its contact with the structure being repaired. To ensure the solidity of the structures being repaired during their re-pair, it is possible to recommend preliminary heating of the plaster solution to a temperature of $60^{\circ} \mathrm{C}$.

The solution was heated by forced electric heating. It was found that the adhesion strength increases maximally at a temperature of $60^{\circ} \mathrm{C}$ by $0.18 \mathrm{MPa}$. At higher heating, the adhesion strength decreases, due to the fact that the setting process of the solution is significantly accelerated and does not allow for high-quality compaction. Presumably, this result is explained by favorable heat and mass transfer processes occurring both in the body of the heated mixture and in the contact area with the «base», where a kind of «migration» of the stucco into the pores of the brickwork. As a result, the contact area increases, a wide contact zone forms, and, as a result, the adhesion strength increases. The fact that heating only the «base» surface is less effective than heating the plaster is proven. Presumably, this is due to the fact that the penetration of the mortar into the pores of the brickwork structure occurs due to the formation of rarefaction of air in them when the stucco is cooled.

It was determined that the simultaneous heating of the solution and the «base» almost does not increase the adhesion strength. The value of the difference in adhesion, in this case, is less than $0.02 \mathrm{MPa}$, which allows us to conclude that this method is ineffective.

Keeping the newly laid plaster layer in the process of hardening under the air-tight shell was also a very effective technological operation. For example, it has been established that the application of an air-tight shell to the surface of a freshly laid plastering layer 
during the initial period of hardening prevents the formation of directional large-capillary porosity of the surface layer, which is a consequence of, on the one hand, intensive evaporation of water (during the hardening of the solution with water being sucked to its surface), and on the other hand, the intake of atmospheric air into the depth of the solution (due to the resulting vacuum in the pores of the solution as a result of the cement hydration reaction).

An appropriate period of holding repair plaster layer in the process of hardening by tight-fitting airtight envelope can be considered as 3-4 days. As an airtight shell recommended polyethylene shell because of its low cost and reusability (turnover). The presence of such a shell on the plaster, restored or build-up on the outer and inner surfaces of brick walls, allows you to save without formwork its shape during the first hours of hardening of the plaster with a layer thickness of up to $3 \mathrm{~cm}$.

In this case, the application of the stucco mortar is carried out by filling it with a cavity formed between the surface of the «base» and the formwork, with its simultaneous compaction with a vibro plate in the contact zone.

The general scheme for the implementation of vibro compaction and «evacuation» of the stucco mortar, which was modeled for the experiment, shown in Fig. 2. The practical implementation of the technology of repair of plaster coating on the outer and inner surfaces of brick walls in case of restoration of the plaster layer is presented in Fig. 2a and in the event of a build-up of the plaster layer is shown Fig. $2 b$.

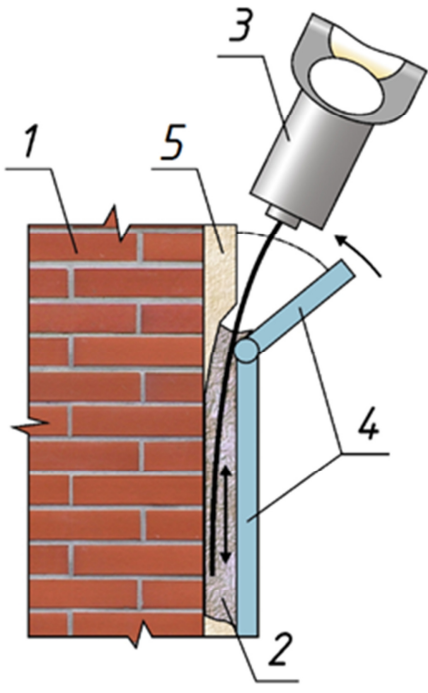

a)

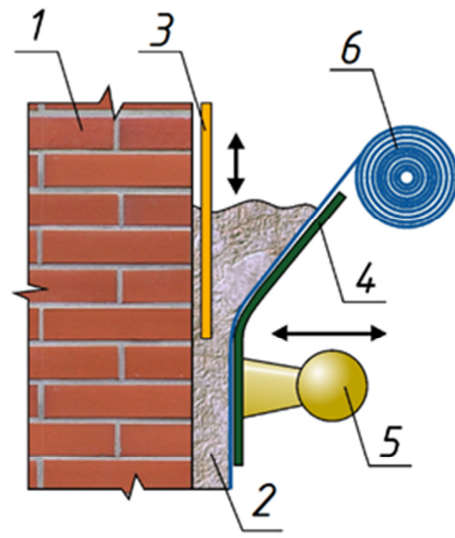

b)

Fig. 2. Scheme of implementation of the technology of repair of plaster coating on the surface of a brick wall: a) when restoring the plaster layer; b) in the event of a build-up of the plaster layer: 1 brick wall construction; 2 - freshly applied plaster; 3 - compactor with vibro plate; 4 - mobile formwork shields; 5 - surface vibrator; 6 - air-tight shell

The formation of the plaster layer is expediently carried out using the formwork, the use of which allows arranging the plaster coating of the required thickness not only on vertical but also on ceiling, including curved surfaces of structures, which is important when plastering religious buildings with a wide variety of architectural forms $[8,9]$. Formwork panels can be fixedly mounted on the surface of the «base» structure and dismantled when the strength of the plaster layer is at least $50 \%$, or move them along the rails as elements of a sliding formwork. 
It is a process of vibration sealing of a plaster coating in the contact zone of a freshly applied plaster mortar with a brickwork structure, which occurs with the help of a specially designed compactor with a vibro plate and the process of evacuating the plaster mortar consists in applying an airtight shell to the plaster layer under the formwork structure.

The peculiarity of plaster repair technology on the exterior and interior surfaces of brick walls in both cases implies:

1. The use of preheated plaster;

2. Molding the plaster layer using formwork;

3. Compaction of the plaster in the contact area with a repaired construction of the brick wall with a vibrator.

\section{Results}

The positive properties of the technology of plaster coating repair on the surface of a brick wall include the following:

1. Molding plaster layer by means of the adjustable shield casing, allowing organizing any plaster layer thickness not only in vertical but also on the ceiling surfaces of the repaired structure of complex shape;

2. Formwork boards fixedly mounted on the surface of the repaired masonry and removed those 3-4 days after plastering;

3. The function of the airtight shell is performed by formwork panels made of a polymeric or metallic material;

4. The deep vibrator is a bending spring $0.3-0.5 \mathrm{~m}$ long and $0.05-0.15 \mathrm{~mm}$ wide, connected at one end to a hand-held electromagnetic vibrator. Its other end moves freely. The springing properties of the working body are necessary to ensure its constant contact with the surface of the repaired structure (regardless of its evenness and position in space), and at the end of the vibration, it is necessary to restore its original straight-line shape.

It is proposed to build up the plaster coating using a sliding formwork with a receiving bin, on which two vibrators (one surface and the other deep with a working body in the form of a rigid plate) and a roll with an airtight (polyethylene) shell are fixed. A sliding formwork with a bunker filled with plaster, with working compactors vibrators, is moved from bottom to top at a speed of 14-18 mm/s, forming a layer of plaster no more than 30 $\mathrm{mm}$ thick, tightly covered with an air-tight shell.

\section{Conclusions}

According to the results of the study has been obtained and developed a patent for utility model «Weatherproof plaster of the external brick wall of the heated building» [10].

The results of tests for water resistance and frost resistance of plaster coating samples made according to the developed technology showed its high efficiency and expediency of use during repairs on exterior and interior surfaces of brick walls, as a way to significantly and effectively increase their service life.

So, the claimed technology influences the increasing of adhesion strength up to $0.7 \mathrm{MPa}$ (in contrast to the required regulatory in $0.4 \mathrm{MPa}$ ), reaching its value due to the following technological operations: preliminary heat of the plaster mortar or the plastered surface's basis up to $50^{\circ} \mathrm{C}$; the plaster mortar's vibration treatment by the plates' vibrators in the contact with the plastered surface; evacuation of the freshly mixed solution under the tight fitting air-tight membrane during the period of hardening for 3-4 days. 


\section{References}

1.H. McKee, I. L. Springfield, Association of Preservation Technology. An Introduction to Early American Masonry, Stone, Brick, Mortar and Plaster (2017)

2.A. G. Wacker, Creating tomorrow's solutions (2009)

3. Guelberth, C. Rose, D. Chiras. G. Island, B.C., Canada: New Society Publishers. The Natural Plaster Book: Earthen, Lime, and Gypsum Plasters for Natural Homes (2003)

4.Z. V. Kobuliev, A. Sh. Sharifov, M. M. Safarov, ICCE/6, Sixth annual international conference on composites engineering (1999)

5.A. Morrison, O.R., USA: Straw Bale Innovations, LLC. Plastering with Natural Hydraulic Lime (2007)

6. G. Ziegenbalg, K. Brümmer, J . Pianski, ed. by J. Válek, C. Groot, J.J. Hughes, HMC 2010 and RILEM TC 203-RHM final workshop, 1301 - 1309 (2010) e-ISBN: 978-2-35158$112-4$

7. N. Ivannikova, P. Sadchikov, A. Zholobov, ICIT: International Conference on Information Technologies Recent Research in Control Engineering and Decision Making Editors (2019)

8. N. Ivannikova, News of science: Proceedings of materials the international scientific conference, (2015)

9.K. A. Yykova, N. A. Ivannikova, E. A. Zholobova, A. L. Zholobov, A. A. Ivannikov, The Patent of Russia No. 2017119143 for utility model «Weatherproof plaster of the external brick wall of the heated building» (2017).

10. A. Mecke, I. Lee, J.R. Baker jr., M.M. Banaszak Holl, B.G. Orr, Eur. Phys. J. E. 14, 7 (2004)

11. H. Nestle, Construction equipment, structures and technologies, 2 (2007). 